\title{
A Rapid HPLC Analysis for Dermal Penetration: The Case Study of 4- Chloro-3-Methylphenol (CMP) from Metal Working Fluid Trim VX
}

\author{
Lun-Yi Zang, Ana M. Barbero and H. Frederick Frasch
}

\author{
Exposure Assessment Branch, Health Effects Laboratory Division, National Institute for Occupational Safety and \\ Health, Morgantown, WV 26505-2888, USA
}

\begin{abstract}
A rapid and simple HPLC method has been developed for the determination of 4-chloro-3-methylphenol (CMP) in the metal working fluid (MWF), Trim VX and in experiments designed to measure the dermal penetration of CMP from MWF. The method used 2-methyl-4,6-dinitrophenol as an internal standard (IS). Water was used as the extraction solvent. The retention times of CMP and internal standard (IS) were 5.56 and 6.67 min, respectively. The standard plots of CMP are linear over the range of $62.5-2,500 \mathrm{ng} \cdot \mathrm{mL}^{-1}$ with correlation coefficients of 0.999 . The limit of quantification (LOQ) for CMP was estimated to be $62.5 \mathrm{ng} \cdot \mathrm{mL}^{-1}$ and the limit of detection (LOD) was approached to be $20 \mathrm{ng} \cdot \mathrm{mL}^{-1}$. Reproducibility of the sample handling and HPLC analysis had a relative standard deviation (RSD) of less than $6 \%$. The average recoveries for the analyte in Trim VX were better than $92 \%$. Using the method, we found that Trim VX contains 2\% CMP. In our preliminary dermal penetration study, the permeability coefficient $k_{p}$ and lag time $\tau$ were estimated to be $4.88 \times 10^{-3} \mathrm{~cm} \cdot \mathrm{h}^{-1}$ and $1.65 \mathrm{~h}$, respectively.
\end{abstract}

Keywords: CMP, MWFs, HPLC.

\section{INTRODUCTION}

4-chloro-3-methylphenol (CMP) is widely used as a preservative in a large number of commercially available products and preparations such as metal working fluids (MWFs), construction materials, medicine and glue [1-10]. About one hundred million gallons of MWFs are produced annually in the United States and over one million workers are exposed to MWFs $[11,12]$. Research has demonstrated that MWFs cause both allergic and irritant contact dermatitis [13-17]. Since it has been found to be an allergen and sensitizer [5-7], CMP may be the crucial species responsible for MWF-induced contact dermatitis. However, no information is available about CMP penetration after MWF dermal exposures.

Trim VX is a water miscible cutting and grinding fluid concentrate manufactured by Master Chemical Corporation, Perrysburg, OH. This product's Material Safety Data Sheet lists two components: petroleum oil $30-40 \%$ and triethanolamine $1-10 \%$. Trim VX is claimed to be nonirritant, and not a sensitizer. However, preliminary studies conducted by investigators in National Institute for Occupational Safety and Health identified the presence of CMP in Trim VX, and this particular MWF was therefore selected by us for further investigation. The interest in this study concerns cutaneous penetration of CMP from MWF. To obtain this information, a suitable HPLC analytical method is needed.

Although there are several methods reported for phenolic compounds in pharmaceuticals and water, these methods

\footnotetext{
*Address correspondence to this author at the Exposure Assessment Branch, Health Effects Laboratory Division, National Institute for Occupational Safety and Health, Morgantown, WV 26505-2888, USA; Tel: (304)2855755; Fax: (304)285-6041; E-mail: hbf9@cdc.gov
}

need specific devices and extraction procedures such as photochemical derivatization [18], enzyme-amperometric probe [19], pre-column derivatization [20], and solid phase extraction (SPE) [21, 22]. These pretreatment procedures add cost and complicate the analysis, require a longer time to complete and generate additional errors as well as waste problems. Although there is a HPLC-UV method for analysis of CMP in Trim VX [23], the chromatograms appear to be overly complicated due to the use of a larger prep column, nonspecific wavelength and complicated organic extraction mixture \& mobile phase. Therefore, the goal of this study was to determine whether or not a pretreatment is necessary for conventional HPLC diodearray-detection (DAD) analysis of CMP in Trim VX and in its dermal penetration studies.

\section{EXPERIMENTAL}

\subsection{Reagents and Materials}

Acetonitrile, ethanol (EtOH), methanol $(\mathrm{MeOH})$, phosphoric acid, sodium bicarbonate, sodium hydroxide, Hepes, diethyl either, 4-chloro-3-methylphenol (CAS: 15972-60-8), and 2-methyl-4,6-dinitrophenol (CAS: 534-521) are all analytical grade and were purchased from Sigma Chemical Co. (St. Louis, MO, USA). 2-methyl-4,6dinitrophenol $\left(1 \mathrm{~g} \cdot \mathrm{mL}^{-1}\right.$ in $\left.\mathrm{MeOH}\right)$ was used as an internal standard (IS). Hanks's Balanced Salt Solution (HBSS) was purchased from Gibco-Invitrogen Corporation (Carlsbad, CA, USA). Water (HPLC grade $\mathrm{H}_{2} \mathrm{O}$ ) was purchased from Fisher scientific (West Chester, PA, USA). Oasis HLB extraction cartridges $(1 \mathrm{cc}, 30 \mathrm{mg})$ were purchased from Waters Co., (Milford, MA, USA).

\subsection{Instrumentation}

The HPLC system was an Agilent 1100 series instrument that consisted of a solvent degasser (Model G1322 A), a 
solvent delivery quaternary pump system (G1311 A), a diode array detector (G1315 A), an analyte fraction collector (G1364 C), a thermal controlled column compartment (G1316 A) and an autosampler (G1329 A) with a stream switching valve and a temperature control unit. The instrument control, data acquisition and analyses were performed using Agilent ChemStation Rev. A.10.01 software. The instrument can record not only all chromatograms, but also all UV spectra at every retention time simultaneously. The HPLC was fitted with an Onyx $\mathrm{C}_{18}$ column, $3.5 \mu \mathrm{m}$ particle size, $100 \mathrm{~mm} \times 4.6 \mathrm{~mm}$ (Phenomenex Inc. USA).

\subsection{Preparation of MWF Trim VX Mixtures}

A $1 \mathrm{mg} \cdot \mathrm{mL}^{-1}$ of Trim VX was prepared in different solvents (water or methanol or ethanol or acetonitrile) by vortex for $1 \mathrm{~min}$, respectively. Then, the individual stock mixture was diluted into the desired concentrations with water for tests as indicated in the results.

\subsection{Solid-Phase Extraction}

SPE was used to concentrate diluted samples and to test whether or not it was needed for our study. SPE was performed on an extraction vacuum manifold using Waters Oasis HLB extraction cartridge (1 cc, $30 \mathrm{mg})$. Before extraction, each cartridge was conditioned with $1.5 \mathrm{~mL}$ mixture of diethyl ether and $\mathrm{MeOH}(\mathrm{v}: \mathrm{v}=9: 1)$ and then rinsed with $1 \mathrm{~mL} \mathrm{MeOH}$ followed by $1 \mathrm{~mL}$ water. All samples with and without internal standard (IS) were adjusted to $\mathrm{pH} 2.0$ with phosphoric acid. The sample volume could be applied from $1 \mathrm{~mL}$ to $20 \mathrm{~mL}$ depending upon the sample concentration (we tested up to $20 \mathrm{~mL}$ of water samples). Each sample was then entirely loaded onto the individual cartridge with the vacuum released and then drawn through at $12.7 \mathrm{~mm} \mathrm{Hg}$ until dryness. Subsequently, 1 $\mathrm{mL} \mathrm{H}_{2} \mathrm{O}$ was added to each cartridge to wash out certain impurities. After this step, the vacuum was increased to 127 $\mathrm{mm} \mathrm{Hg}$ until dryness of all cartridges. Then the waste test tubes were replaced by the new clean collection tubes. The target compound was recovered by eluting the sorbent using $2 \times 0.75 \mathrm{~mL}$ of diethyl ether containing $10 \% \mathrm{MeOH}$ at 12.7 $\mathrm{mmHg}$ of vacuum. The eluent was evaporated by $\mathrm{N}_{2}$ blow down. The residue was reconstituted to $500 \mu \mathrm{L}$ with water or mobile phase $\left(50 \%\right.$ acetonitrile- $50 \% \mathrm{H}_{2} \mathrm{O}$ containing $0.1 \%$ $\mathrm{H}_{3} \mathrm{PO}_{4}$ ) and vortexed for $\sim 30$ s. making the sample ready for HPLC analysis.

\subsection{HPLC Assay}

The analysis of CMP was carried out on an Agilent 1100 HPLC system operating at ambient temperature at a constant flow rate of $0.5 \mathrm{~mL} \cdot \mathrm{min}^{-1}$ with a constant isocratic of mobile phases of $50 \%$ acetonitrile and $50 \% \mathrm{H}_{2} \mathrm{O}$ containing $0.1 \%$ $\mathrm{H}_{3} \mathrm{PO}_{4}$. A $10 \mu \mathrm{L}$ aliquot of the extracted sample was injected onto the HPLC column. The eluents were delivered to the diode array detector (DAD), which was operated with different channels at 228 and $281 \mathrm{~nm}$, respectively. Analytes were detected by DAD and all scanned spectra were recorded from $190 \mathrm{~nm}$ to $360 \mathrm{~nm}$.

\subsection{Quantification}

Quantitative analysis was performed using ChemStation software to develop a processing method and automatically measure the response of the HPLC system to the compounds in a sample. The response measurement was taken from the area under each peak and was determined by an integration calculation. Quantification of CMP was done using the 2methyl-4,6-dinitrophenol as the IS because of its good stability, solubility and proper retention time. CMP standard is stable in aqueous stock solution for months and in Trim VX for years at room temperature. The responses of CMP and IS were measured at their individual peak retention times, 5.56 and $6.67 \mathrm{~min}$, respectively. The amount of CMP was determined using a calibration plot generated at different concentrations with five replicate samples.

\subsection{Statistical Analyses}

Statistical analyses of data were made using SigmaStat (Systat Software, Inc, San Jose, CA). Data presented are the means \pm standard deviations of values compared. The precision of the assay was determined using five replicate samples of Trim VX spiked with a known amount of standard analyte in the presence of a fixed amount of IS.

\subsection{Preparation of Guinea Pig Skin and Penetration Experiment}

Male hairless guinea pigs of the strain Crl:IAF(HA)-hr were obtained from Charles River Laboratories (Wilmington, MA) and their uses were approved by our Animal Care and Use Committee. The guinea pigs (500-670 g) were euthanized with $\mathrm{CO}_{2}$ and abdominal skin was harvested and stored frozen at $-85^{\circ} \mathrm{C}$ until use. On the day of use, skin was thawed and underlying muscle and fat were dissected free. The skin was dermatomed at $315 \mu \mathrm{m}$ setting using a Padgett Dermatome Model B (Integra Lifesciences Corp. Plainsboro, NJ). Skin disks (3/4") were cut using a stainless steel punch.

The assembly of equipment used for the dermal penetration studies was identical to previously reported [24]. The penetration experiments were performed with Franztype static diffusion cells that consist of donor and receptor compartments. The skin disks were mounted in pre-warmed $\left(37{ }^{\circ} \mathrm{C}\right)$ diffusion cell which were pre-filled with Hepesbuffered Hank's balanced salt solution ( $\mathrm{pH}$ 7.4). The receptor volume was $5 \mathrm{~mL}$ and the diameter of exposed skin was $9 \mathrm{~mm}$. The donor compartments were filled with $20 \%$ Trim VX aqueous mixture. Samples were collected from receptor compartments hourly for a $5 \mathrm{hr}$ exposure time.

\section{RESULTS AND DISCUSSION}

\subsection{Chromatograms and Spectra of 4-Chloro-3- Methylphenol}

Fig. (1) shows the HPLC results and UV spectra of the standard CMP, Trim VX aqueous extract and CMP spiked Trim VX, respectively. The chromatogram in Fig. (1a) contains two major peaks that were obtained in a standard mixture consisting of CMP $\left(1.25 \mu \mathrm{g} \cdot \mathrm{mL}^{-1}\right)$ and IS (2.5 $\left.\mu \mathrm{g} \cdot \mathrm{mL}^{-1}\right)$ in water. The first peak exhibits a retention time of 5.56 min which is contributed by CMP. The UV spectrum (see inset plot) corresponding to this peak exhibits three absorption peaks at 192, 228, and $281 \mathrm{~nm}$, respectively, which is consistent with the spectrum of CMP standard along (data not shown). Since the CMP can be detected at more than one wavelength, and its peaks have a constant 


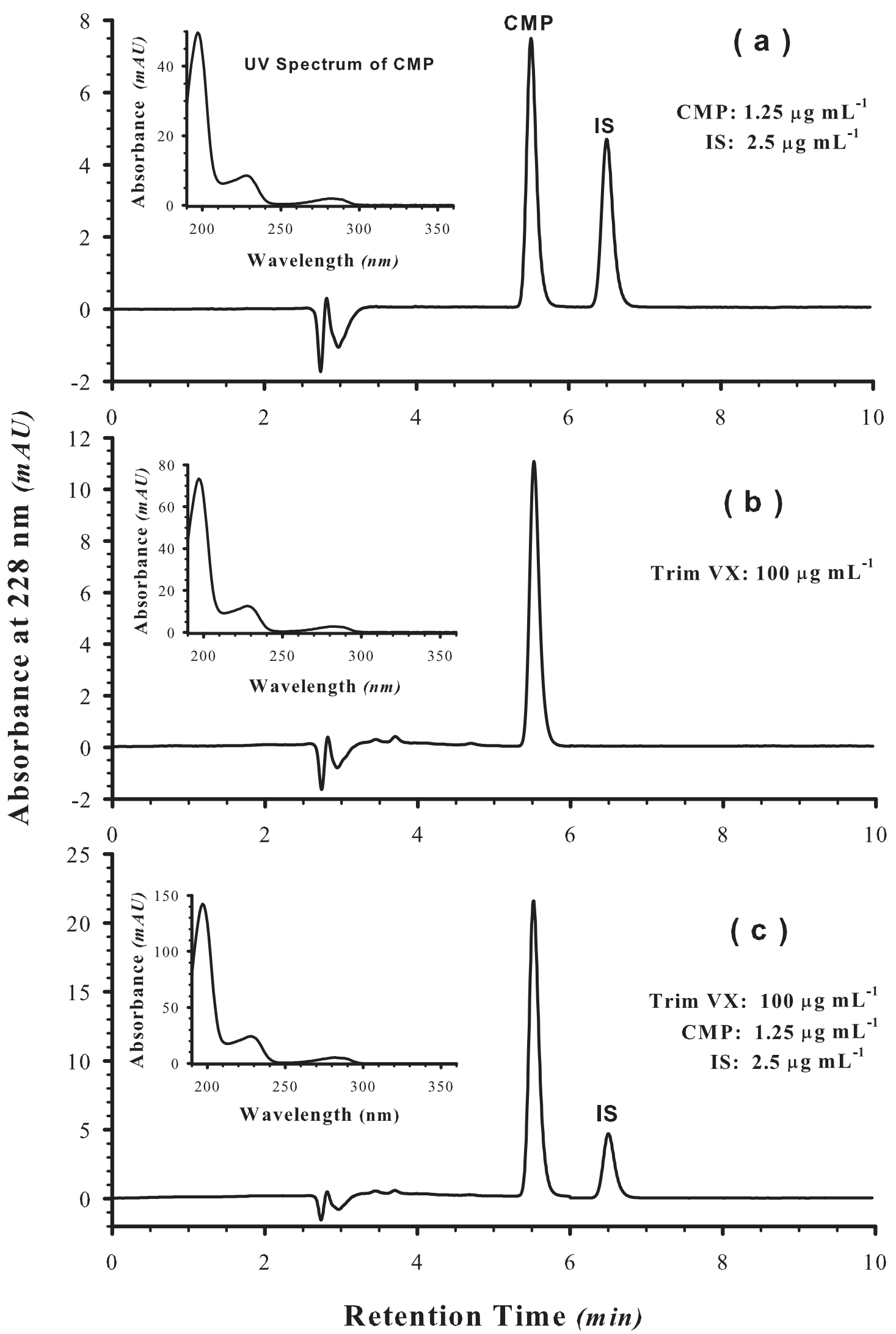

Fig. (1). HPLC chromatograms and spectra of 4-chloro-3-methylphenol. The chromatograms and spectra were obtained from the mixtures as indicated in Figures. The mixtures contain: (a) $1.25 \mu \mathrm{g} \cdot \mathrm{mL}^{-1}$ of standard CMP and $2.5 \mu \mathrm{g} \cdot \mathrm{mL}^{-1}$ of internal standard (IS); (b) $100 \mu \mathrm{g} \cdot \mathrm{mL} \mathrm{L}^{-1}$ of Trim VX in $\mathrm{H}_{2} \mathrm{O}$; and (c) $100 \mu \mathrm{g} \cdot \mathrm{mL}^{-1}$ of Trim VX and $1.25 \mu \mathrm{g} \cdot \mathrm{mL}^{-1}$ of CMP in the presence of $2.5 \mu \mathrm{g} \cdot \mathrm{mL}^{-1}$ internal standard. The HPLC settings are described in section 2.2.1 (HPLC assay). 
response ratio for specific wavelengths, the wavelength 228 $\mathrm{nm}$ with greater absorbance was used for quantification.

The second peak observed at a retention time of $6.67 \mathrm{~min}$ resulted from IS and its UV spectrum exhibits two absorption peaks at 213 and $268 \mathrm{~nm}$ (data not shown). The stronger $228 \mathrm{~nm}$ wavelength for CMP is in the valley between the peaks of the IS.

The chromatogram shown in Fig. (1b) was obtained from the aqueous extract of Trim VX alone. The predominant peak was found at the retention time of $5.56 \mathrm{~min}$ which is consistent with standard CMP. UV spectrum recorded for this peak is consistent with the standard CMP as shown in Fig. (1a). It is evident that the component of the peak at the retention time $5.56 \mathrm{~min}$ in Trim VX resulted from CMP.

To further confirm the peak at retention time $5.56 \mathrm{~min}$ resulting from CMP, we added an indicated amount of standard CMP into Trim VX aqueous mixture and compared the chromatograms and spectra obtained from the standard CMP mixture and CMP spiked Trim VX under the same condition. As depicted in Fig. (1c), the chromatogram observed in the presence of $100 \mu \mathrm{g} \cdot \mathrm{mL}^{-1}$ Trim VX and 1.25 $\mu \mathrm{g} \cdot \mathrm{mL}^{-1} \mathrm{CMP}$ only shows a single peak at $5.56 \mathrm{~min}$, which is similar to that obtained in Fig. (1a, b). This result indicates that the peak at 5.56 min observed in Trim VX could be attributed to CMP.

When the organic mobile phase fraction was increased to $70 \%$, the peak from CMP spiked Trim VX and IS had shorter retention time (data not shown). However, the interval between the peaks of the target and IS was small and affected quantification. Although increasing the aqueous mobile phase fraction to $70 \%$ gave a very good separation, it increased the analysis time to $15 \mathrm{~min}$ for each run.
Therefore, $50 / 50$ of organic/aqueous mobile phase was selected for all tests.

\subsection{Comparison of Calibration Plots}

Fig. (2) shows the calibration plots of standard CMP with and without SPE in the presence of IS, respectively. The calibration plots for CMP determination were linear over the concentration range from 0.0625 to $10 \mu \mathrm{g} \cdot \mathrm{mL}^{-1}$ (here shown 0.125 to $2.5 \mu \mathrm{g} \cdot \mathrm{mL}^{-1}$ ). Linearity of CMP to chromatographic response was verified by calculating the correlation coefficient $(R)$ for the calibration plots. Each correlation coefficient was estimated using 5 points. As shown in Fig. (2), each plot gave a straight line with $R$ values closer to 1 (see the results in the Fig. (2)).

Comparing the calibration plots of standard CMP with and without SPE in the presence of IS, we found that the data obtained with SPE are similar to those without SPE in the tested range except for a slightly larger error. It might be due to the greater number operation steps and differences among individual SPE cartridge. If the analyte concentration in a sample is lower than $62.5 \mathrm{ng} \cdot \mathrm{mL}^{-1}$ in our tested range, it is necessary to use SPE to concentrate the analyte for assay. If the analyte concentration is larger than this level, it is not necessary to use SPE. The following tests were performed without SPE.

\subsection{Intra-Day and Inter-Day Variation}

The intra-day and inter-day validations of the method were performed with five and fifteen replicates of each quality control sample, respectively. The tests for inter-days were performed over 5 days. The results are summarized in Table 1. The method is reproducible with good percentage of relative standard deviation $(\% R S D)$ from $1.2 \%$ to $5.6 \%$ for

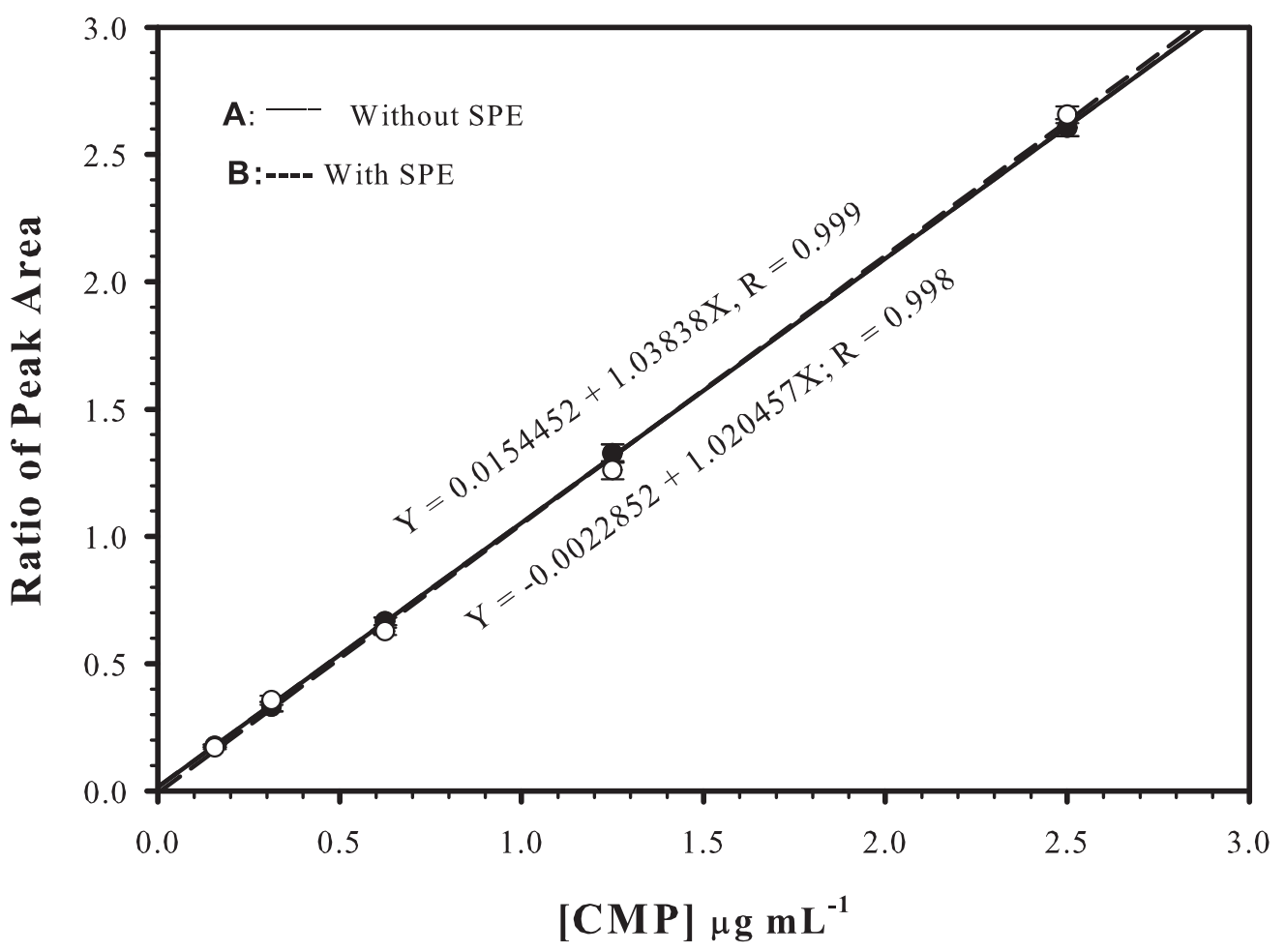

Fig. (2). Comparison of calibration plots of 4-chloro-3-methylphenol obtained in standard spiked Trim VX $\left(50 \mu \mathrm{g} \cdot \mathrm{mL}^{-1}\right) \mathrm{mixtures}$ with and without solid phase extraction in the presence of internal standard $\left(2.5 \mu \mathrm{g} \cdot \mathrm{mL}^{-1}\right)$. 
the intra-day validation, $2.4 \%$ to $5.2 \%$ for the inter-day validation. Also, the method generates the standard accuracy from $96.5 \%$ to $99.8 \%$ for intra-day and from $94.7 \%$ to $98.3 \%$ for inter-day, respectively.

Table 1. Summary of the Assay Validation Data

\begin{tabular}{|l|c|c|c|}
\hline \multicolumn{1}{|c|}{ [CMP] } & $\mathbf{0 . 6 2 5} \mathbf{\mu g} \cdot \mathbf{m L}^{-\mathbf{1}}$ & $\mathbf{1 . 2 5} \mathbf{\mu g} \cdot \mathbf{m L}^{-\mathbf{1}}$ & $\mathbf{2 . 5} \mathbf{\mu g} \cdot \mathbf{m L}^{-1}$ \\
\hline \hline Intra-day $(n=5)$ & & & \\
Measured Mean $\left(\mu \mathrm{g} \cdot \mathrm{mL}^{-1}\right)$ & 0.65 & 1.22 & 2.50 \\
$S D$ & 0.04 & 0.03 & 0.03 \\
$R S D(\%)$ & 5.6 & 2.7 & 1.2 \\
Accuracy (\%) & 96.5 & 97.3 & 99.8 \\
\hline & & & \\
Inter-day ( $n=15)$ & & & \\
Measured Mean $\left(\mu \mathrm{g} \cdot \mathrm{mL}^{-1}\right)$ & 0.59 & 1.25 & 2.54 \\
$S D$ & 0.03 & 0.05 & 0.06 \\
$R S D$ (\%) & 5.2 & 3.6 & 2.4 \\
Accuracy (\%) & 94.7 & 99.8 & 98.3 \\
\hline
\end{tabular}

\subsection{Recovery of CMP in Trim VX}

To further examine the reliability of the developed method for CMP in MWF Trim VX, we performed an experiment using the internal addition method [25] and calculated the recoveries of CMP. Each of three levels of CMP was mixed with constant concentration of Trim VX $\left(50 \mu \mathrm{g} \cdot \mathrm{mL}^{-1}\right)$ in the presence of fixed amount of IS $(2.5$ $\left.\mu \mathrm{g} \cdot \mathrm{mL}^{-1}\right)$. Each level of CMP, Trim VX aqueous mixture and CMP spiked Trim VX were analyzed in five replicates $(n=5)$, respectively. Recoveries were calculated by the average values from CMP spiked Trim VX divided by the sum of values from CMP and Trim VX. The results are listed in Table 2. Since $\%$ RSD from all tests are in the range of $<5 \%$, the standard deviations from each set of samples are acceptable. Although the value of $93 \%$ for CMP recovery in high level spiked Trim VX is slightly low and 103\% at low level seems slightly high, the values are acceptable. These results indicate that the method is reliable.

Table 2. Recoveries of CMP in MWF Trim VX by Internal Addition Method

\begin{tabular}{|c|c|c|c|}
\hline CMP Spiked Level & $\mathbf{0 . 6 2 5} \boldsymbol{\mu} \mathbf{g} \cdot \mathbf{m L} \mathbf{~}^{-1}$ & $\mathbf{2 . 5} \boldsymbol{\mu} \mathbf{g} \cdot \mathbf{m L}^{\mathbf{1}}$ & $\mathbf{1 0} \boldsymbol{\mu} \mathbf{g} \cdot \mathbf{m L}$ \\
\hline \hline CMP $(n=5)$ & $0.61 \pm 0.02$ & $2.40 \pm 0.05$ & $9.47 \pm 0.10$ \\
Trim VX $(n=5)$ & $0.98 \pm 0.02$ & $0.98 \pm 0.02$ & $0.98 \pm 0.02$ \\
CMP/Trim VX $(n=5)$ & $1.62 \pm 0.06$ & $3.20 \pm 0.14$ & $9.69 \pm 0.34$ \\
\% Recovery & 102.5 & 95 & 92.8 \\
\hline
\end{tabular}

\subsection{Limits of Detection and Quantitation}

The limit of detection (LOD) was determined by detecting the analyte signal at a confidence level that approaches the mean blank signal plus three times standard deviation of the blank [26, 27]. Twenty-five blank measurements were performed over five days. The LOD was estimated to be $20 \mathrm{ng} \cdot \mathrm{mL}^{-1}$. The limit of quantification (LOQ) was obtained by determining the lowest amount of analyte at a signal to noise ratio of 10 using the standard compound $[26,27]$. LOQ was estimated to be $62.5 \mathrm{ng} \cdot \mathrm{mL}^{-1}$.

\subsection{Determination of CMP in MWF Trim VX}

To measure CMP in Trim VX, we determined six dilutions of Trim VX at $n=5$ for each concentration and plotted the measured CMP (using calibration curve) against Trim VX concentrations. If the method is reliable, the measured CMP should increase linearly with the amount of Trim VX, and the plot of CMP versus the amount of Trim VX would give a straight line with a constant slope and a high correlation coefficient. As shown in Fig. (3), the detected CMP increased as a function of Trim VX concentration, the plot gave a straight line $(Y=-0.00062+$ $0.02075 X$ ) with an excellent correlation coefficient of 0.9997 . The relative standard deviation values for all tested levels of analyte varied within $\pm 5 \%$. This indicates that the method is reliable and may be applied to ongoing in vitro biotransformation studies.

Since there is a quantitative relationship between the measured CMP and Trim VX, the amount of CMP can be related to the concentration of Trim VX by the equation.

$Y=A+b X$

where $A$ is the intercept on $y$ axis; $b$ is the slope of the plot and $X$ is the value on $x$-axis. An $A$ value less than 0.001 can be considered negligible and the concentration of the analyte can be obtained directly from item $b X$. Obviously this method is better than single level assay. Since the solubility of CMP in different solvents is different [The Merck Index, $17^{\text {th }}$ Edition], we determined CMP extracted with different solvents from Trim VX and results are shown in Table 3. If the amounts measured from these extracts are similar, the average value should be close to the true amount of CMP in Trim VX. As shown in the table, the data obtained from these four solvents are within the coefficient of variation $(\mathrm{CV})$ of the assay. The average value is $2.00 \pm 0.04 \%(\mathrm{w} / \mathrm{w})$. Therefore, we can estimate that Trim VX contains $2.00 \%$ of CMP.

Table 3. Determined Amount of CMP in Trim VX with Different ExtractionSolvents

\begin{tabular}{|c|c|c|c|}
\hline Solvent & $\begin{array}{c}{[\text { Trim VX] }} \\
\boldsymbol{\mu g} \cdot \mathbf{m L}^{-1}\end{array}$ & $\begin{array}{c}\text { Measured } \\
\mathbf{C M P} \boldsymbol{\mu g} \cdot \mathbf{m L}^{-1}\end{array}$ & $\begin{array}{c}\text { \% CMP in } \\
\text { Trim VX }\end{array}$ \\
\hline \hline Acetonitrile & 100 & 1.982 & $1.98 \%$ \\
\hline Methanol & 100 & 2.054 & $2.05 \%$ \\
\hline Ethanol & 100 & 2.015 & $2.02 \%$ \\
\hline Water & 100 & 1.951 & $1.95 \%$ \\
\hline
\end{tabular}

\subsection{Application of the Method to Dermal Penetration}

The developed method has been successfully used in our in vitro dermal permeation preliminary studies. Fig. (4) shows high performance liquid chromatograms and UV spectra resulting from the sample collected at exposure time 


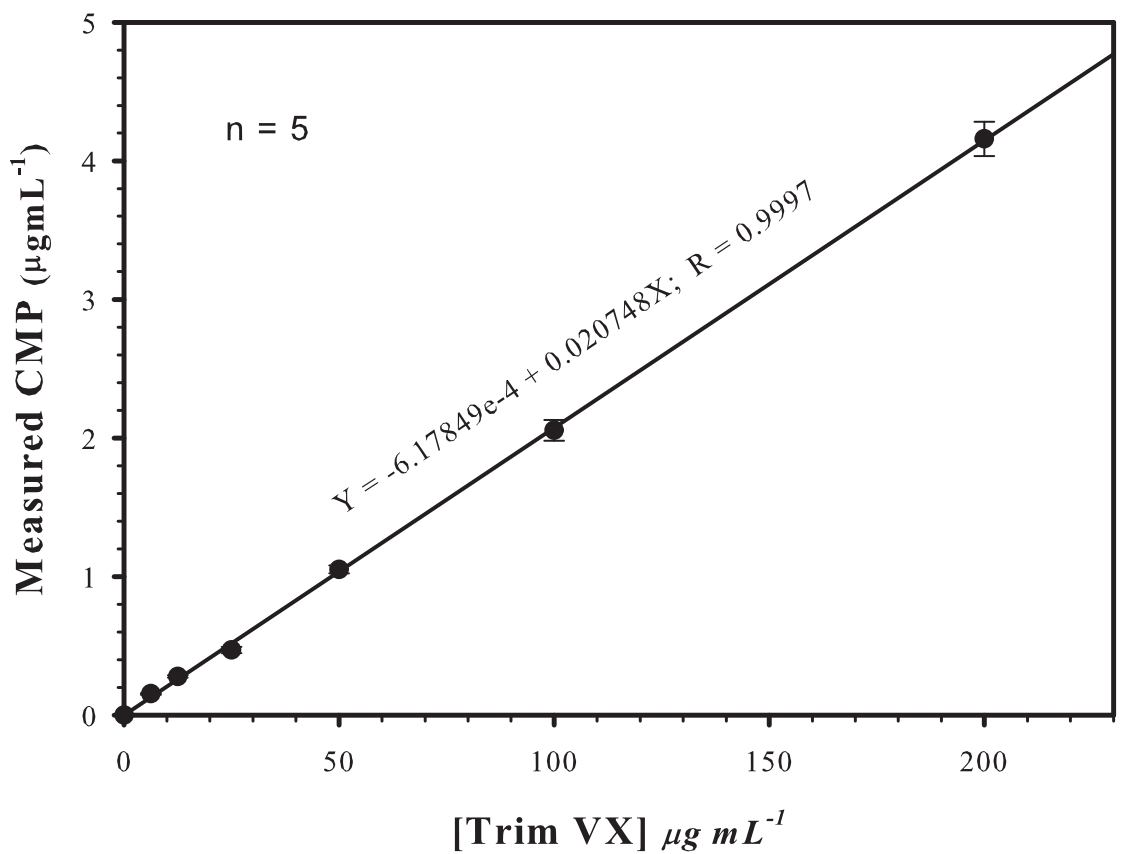

Fig. (3). Determination of 4-chloro-3-methylphenol as a function of Trim VX concentration. Trim VX at indicated concentrations was prepared in HPLC grade water and contained a constant amount of internal standard $\left(2.5 \mu \mathrm{g} \cdot \mathrm{mL}^{-1}\right)$. The amount of 4-chloro-3-methylphenol was extrapolated from the standard plot.

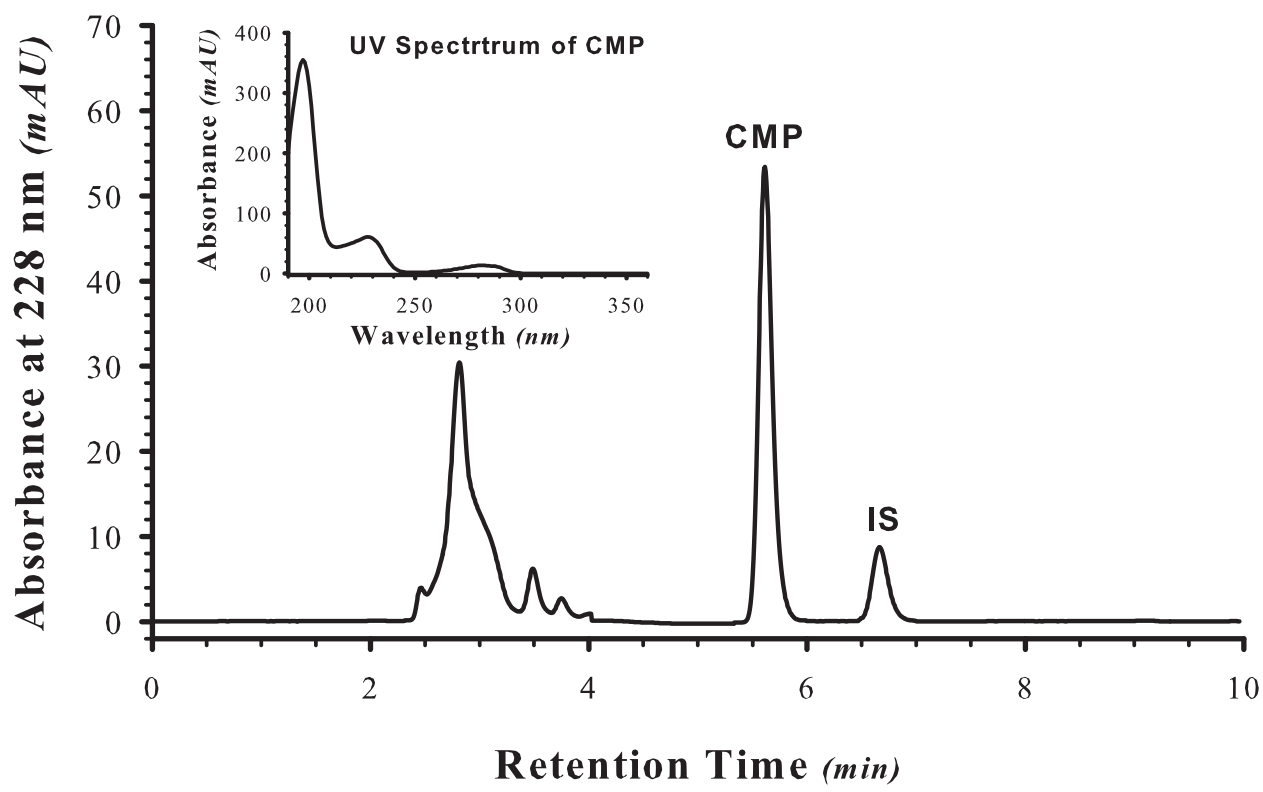

Fig. (4). Chromatogram and spectrum obtained in Trim VX-dermal penetrated receptor solution. Hairless guinea pig skin was exposed to $20 \%$ Trim VX water mixture for two hours.

of $2 \mathrm{~h}$. It is obvious that the chromatogram and UV spectrum in this figure are identical to those in Fig. (1). This result confirmed that the method may be reliably applied to our dermal penetration investigation.

Fig. (5) shows a cumulative penetration curve of CMP from Trim VX as a function of exposure time. Data points represent the means $\pm S D$ of three skin disks. The data were fit to the predictions of the diffusion equation as described in our previous study [28], to yield estimates of the permeability coefficient $k_{p}$ and lag time $\tau$ as shown in this figure. The permeability coefficient and lag time were calculated by nonlinear regression of the following equation, through the mean values in Fig. (5).

$$
m(t)=k_{p} C t-k_{p} C_{1} \tau-\frac{12 k_{p} C \tau}{\pi^{2}} \sum_{n=1}^{\infty} \frac{(-1)^{n}}{n^{2}} \exp \left(\frac{-n^{2} \pi^{2} t}{6 \tau}\right)
$$

where, $m(t)$ is the cumulative amount of chemical penetrated per unit area of skin at time $t$, and $C$ is the donor concentration. There are 2 unknown parameters that 


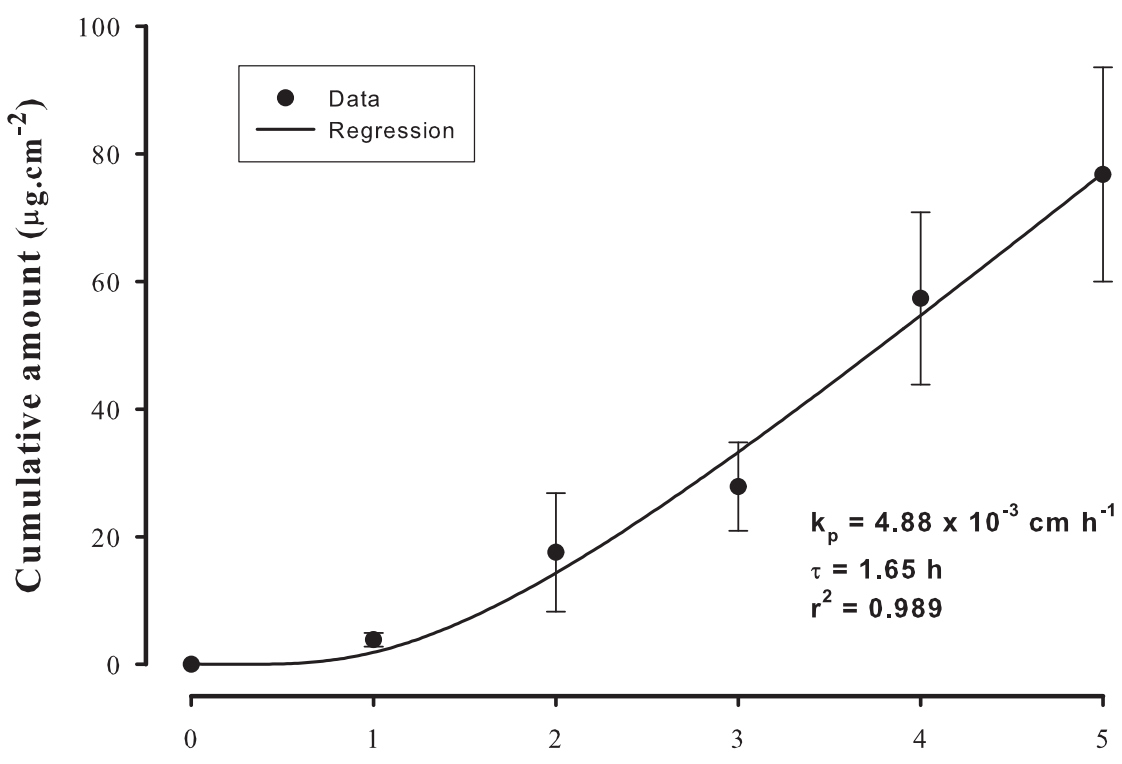

Time (h)

Fig. (5). Dermal penetration rate of 4-chloro-3-methylphenol from Trim VX as a function of exposure time. Hairless guinea pig skin was exposed to $20 \%$ Trim VX water mixture. Data represent mean, SD of three skin disks. Permeability coefficient $\left(k_{p}\right)$ and lag time $(\tau)$ were determined by nonlinear regression of the data with the diffusion equation.

determine the solution of this equation: permeability coefficient $k_{p}$ and lag time $\tau$. Nonlinear regressions of the mass accumulation data with eq. (2) were performed using SigmaPlot 9.01 (Systat Software, Inc.). The equation was truncated to 7 terms in the series. The correlation coefficient of the regression was found to be 0.989 . A permeability coefficient of $4.88 \times 10^{-3} \mathrm{~cm} \cdot \mathrm{h}^{-1}$ was measured. This preliminary study verifies that the method can be applied to ongoing in vitro dermal penetration studies.

\section{CONCLUSION}

The methodology developed in this study has the important advantages of producing a rapid and simple assay. Since biocides are usually added into commercial products at a concentration that kills various microscopic organisms and protects the products from microbial degradation [12], our method of HPLC direct injection is suitable for analysis of CMP during MWFs dermal exposure and also in other products. This method does not require specific devices and provides excellent specificity and good sensitivity, which meet FDA required parameters accuracy, precision, selectivity, sensitivity, reproducibility, and stability for a method validation. It also enables researchers to complete an assay for analytes within a short time. The analysis time is shorter than most other methods.

\section{ABBREVIATIONS}

$\mathrm{CMP}=$ 4-chloro-3-methylphenol

MWFs $=$ Metal working fluid

HPLC = High performance liquid chromatography

\section{DISCLAIMER}

The findings and conclusions in this report are those of the author(s) and do not necessarily represent the views of the National Institute for Occupational Safety and Health.

\section{REFERENCES}

[1] Dooms-Goossens, A.; Degreef, H.; Vanhee, J.; Kerkhofs, L.; Chrispeels, M.T. Chlorocresol and chloracetamide: allergens in medications, glues, and cosmetics. Contact Dermatitis, 1981, 7(1), 51-52.

[2] Mattsby-Baltzer, I.; Sandin, M.; Ahlstrom, B.; Allenmark, S.; Edebo M.; Falsen, E.; Pedersen, K.; Rodin, N.; Thompson, R.A.; Edebo, L. Microbial growth and accumulation in industrial metalworking fluids. Appl. Environ. Microbiol., 1989, 55(10), 26812689.

[3] van Faassen, I.; Verweij-van, Vught, AM.; Lomecky-Janousek, M.Z.; Razenberg, P.P.; van der Veen, EA. Preservatives in insulin preparations impair leukocyte function. In vitro study. Diabetes Care, 1990, 13(1), 71-74.

[4] Blumer, I.R. Severe injection site reaction to insulin detemir Diabetes Care, 2006, 29(4), 946.

[5] Archer, C.B.; MacDonald, D.M. Chlorocresol sensitivity induced by treatment of allergic contact dermatitis with steroid creams. Contact Dermatitis, 1984, 11(3), 144-145.

[6] Lewis, P.G.; Emmett, E.A. Irritant dermatitis from tri-butyl tin oxide and contact allergy from chlorocresol. Contact Dermatitis, 1987, 17(3), 129-132.

[7] Rajpar, S.F.; Foulds, I.S.; Abdullah, A.; Maheshwari, M. Severe adverse cutaneous reaction to insulin due to cresol sensitivity. Contact Dermatitis, 2006, 55(2), 119-120.

[8] Clerx, V.; Van Den Keybus, C.; Kochuyt, A.; Goossens, A. Drug intolerance reaction to insulin therapy caused by metacresol. Contact Dermatitis, 2003, 48(3), 162-163.

[9] de Boer, EM.; van Ketel, WG.; Bruynzeel, D.P. Dermatoses in metal workers. (I). Irritant contact dermatitis. Contact Dermatitis, 1989, 20(3), 212-218.

[10] Cono, J.; Casey, C.G.; Bell, D.M. Smallpox vaccination and adverse reactions. Guidance for clinicians. MMWR Recomm. Rep., 2003, 52(RR-4), 1-28.

[11] Ma, I.L. Report on the volume of lubricants manufactured in the United States and Canada by independent lubricant manufactures association in 1999. Alexandria, VA: Independent Lubricant Manufactures Association, 2000.

[12] National Institute for Occupational Safety and Health Metalworking Fluids. NIOSH, USA, 2006.

[13] Li, K.; Aghazadeh F.; Hatipkarasulu S.; Ray T.G. Health risks from exposure to metal-working fluids in machining and grinding operations., Int. J. Occup. Saf. Ergon., 2003, 9(1), 75-95. 
[14] Madan V.; Beck M.H. Occupational allergic contact dermatitis from N,N-methylene-bis-5-methyl-oxazolidine in coolant oils. Contact Dermatitis, 2006, 55(1), 39-41.

[15] Piebenga, W.P.; van der Walle, H.B. Allergic contact dermatitis from 1-[2-(2,4-dichlorophenyl)-2-(2-propenyloxy) ethyl]-1Himidazole in a water-based metalworking fluid. Contact Dermatitis, 2003, 48(5), 285-286.

[16] Sprince, N.L.; Palmer, J.A.; Popendorf, W.; Thorne, P.S.; Selim, M.I.; Zwerling, C.; Miller, E.R. Dermatitis among automobile production machine operators exposed to metal-working fluids. Am. J. Ind. Med., 1996, 30(4), 421-429.

[17] de Boer, E.M.; van Ketel, W.G.; Bruynzeel, DP. Dermatoses in metal workers. (II). Allergic contact dermatitis. Contact Dermatitis, 1989, 20(4), 280-286.

[18] Di Pietra, A.M.; Andrisano, V.; Gotti, R.; Cavrini, V. On-line postcolumn photochemical derivatization in liquid chromatographicdiode-array detection analysis of binary drug mixtures. J. Pharm. Biomed. Anal., 1996, 14(8-10), 1191-1199.

[19] Campanella, L.; Sammartino, M.P.; Sbrilli, R.; Tomassetti, M. Analytical comparison of an enzyme-amperometric method for chlorocresol determination in ointments with colorimetry and liquid chromatography. J. Pharm. Biomed. Anal., 1992, 10(10-12), 751-755.

[20] Gatti, R.; Roveri, P.; Bonazzi, D.; Cavrini, V. HPLC-fluorescence determination of chlorocresol and chloroxylenol in pharmaceuticals. J. Pharm. Biomed. Anal., 1997, 16(3), 405-412.

[21] Frebortova, J. Determination of chlorophenols in soils by a method involving alkaline extraction and solid phase preconcentration prior to high-performance liquid chromatography. Biosci. Biotechnol. Biochem., 1995, 59(10), 1930-1932.

[22] Kladi, M.; Dassenakis M.; Scoullos M.; Psaroudakis N. Determination of phenols in natural waters by solid phase extraction implemented by gas and liquid chromatography. Fresen. Environ. Bull., 2006, 15(9A), 1003-1008.

[23] Brown, K.K.; Robinson, K. High-performance liquid chromatography identification, quantification, and fractionation of a suspect allergen, 4-chloro-3-methylphenol, in an LLNA-positive metalworking fluid. Tribol. Trans., 2008, 51(1), 101-106.

[24] Frasch, H.F.; Barbero, A.M.; Alachkar H.; McDougal J.N. Skin penetration and lag times of neat and aqueous diethyl phthalate, 1,2-dichloroethane and naphthalene. Cutan. Ocul. Toxicol., 2007, 26(2), 147-160.

[25] Zang, L.Y.; Kalbach, H.L.; Brown, B.; Jackson, L.L.; van Kuijk, F.J. Elimination of n-butylated hydroxytoluene methylation during fatty acid analysis by gas chromatography. J. Chromatogr. B Biomed. Appl., 1996, 677(2), 209-216.

[26] Miller, J.N.; Miller, J.C. Statistics and Chemometrics for Analytical Chemistry. Pearson Education, Prentice Hall, UK, 2000.

[27] Skoog, D.A.; Leary, J.J. Principles of Instrumental Analysis, Harcourt Brace College Publishers, USA, 1992.

[28] Frasch, H.F.; Barbero, A.M. Application of solid-phase microextraction to in vitro skin permeation experiments: example using diethyl phthalate. Toxicol. In Vitro, 2005, 19(2), 253-259.

(C) Zang et al.; Licensee Bentham Open.

This is an open access article licensed under the terms of the Creative Commons Attribution Non-Commercial License (http://creativecommons.org/licenses/by-nc/ $3.0 /$ ) which permits unrestricted, non-commercial use, distribution and reproduction in any medium, provided the work is properly cited. 